Tropical Journal of Pharmaceutical Research January 2016; 15 (1): 195-200

ISSN: $1596-5996$ (print); 1596-9827 (electronic) (c) Pharmacotherapy Group, Faculty of Pharmacy, University of Benin, Benin City, 300001 Nigeria.

\title{
Prevalence of Risk Factors for Coronary Artery Disease in Southern Punjab, Pakistan
}

\author{
Muhammad Shoaib Khan ${ }^{1}$, Ajwad Khan ${ }^{1}$, Atif $\mathrm{Ali}^{2 \star}$, Naveed Akhtar ${ }^{1}$, Fatima \\ Rasool $^{3}$, Hira Khan ${ }^{1}$, Nisar ur Rehman ${ }^{2}$ and Sajid Hussain Shah ${ }^{4}$ \\ ${ }^{1}$ Department of Pharmacy and Alternative Medicine, The Islamia University of Bahawalpur 63100, Bahawalpur, ${ }^{2}$ Department of \\ Pharmacy, COMSATS Institute of Information Technology, Abbottabad 22060, ${ }^{3}$ University College of Pharmacy, The University \\ of Punjab, Lahore, ${ }^{4}$ Department of Environmental Sciences, COMSATS Institute of Information Technology, Abbottabad 22060, \\ Pakistan \\ *For correspondence: Email: ajmaline2000@gmail.com
}

\begin{abstract}
Purpose: To explore the prevalence of risk factors for coronary artery disease (CAD) in Southern Punjab, Pakistan.

Methods: A cross-sectional survey was conducted for the prevalence of risk factors for CAD among 200 patients admitted at the different hospitals of Southern Punjab, Pakistan from December 2012 to April 2013. A questionnaire was used to collect data, including demographic information, family health history, dietary habits, physical activity and tobacco use. History of hypertension, diabetes mellitus (DM) or its treatment was recorded after observing their medical reports.

Results: The proportion of females and males was 65.53 and $34.46 \%$, respectively. Of the 200 patients, the mean age of males was 52.7 years and 55.8 years for females. The most prevalent coronary artery risk factors were physical inactivity (52.5\%), hypertension (52\%), poor dietary habits (48.5\%), fatty food consumption (47.5\%), obesity (38\%) and smoking (37\%), respectively. Other less common risk factors were diabetes (30\%) and family history of CAD (20\%).

Conclusion: CAD was seen in only $20 \%$ of the subjects; the prevalence of individual risk factors ranged from 30 to $52.5 \%$ and can be improved by encouraging the patients to adopt a healthy life style.
\end{abstract}

Keywords: Risk factors, Prevalence, Coronary artery disease, Diabetes, Southern Punjab

Tropical Journal of Pharmaceutical Research is indexed by Science Citation Index (SciSearch), Scopus, International Pharmaceutical Abstract, Chemical Abstracts, Embase, Index Copernicus, EBSCO, African Index Medicus, JournalSeek, Journal Citation Reports/Science Edition, Directory of Open Access Journals (DOAJ), African Journal Online, Bioline International, Open-J-Gate and Pharmacy Abstracts

\section{INTRODUCTION}

Progressive expansion and acceptance of a western life style contributes to the rising burden of cardiovascular disease (CVD) in the developing world, including Pakistan [1]. The 'exclusive' disease, which was once restricted to the wealthy class, is now increasingly involving people from lower socio-economic sections especially the younger age groups [2]. The risk factors of CAD, if identified at an early stage can be extremely useful in planning primary and secondary preventive strategies. A major chunk of government resources can be saved which would otherwise be spent for investigation and treatment of patients with CAD and its complications [3].

In South Asia the prevalence of hypertension is $3.2 \%$, diabetes $2.6 \%$, and CAD is $3.2 \%$. However, in urban and immigrant populations the prevalence rates are $12-20,6-8$, and $7-14$ $\%$, respectively. Mean serum cholesterol level is $180-200 \mathrm{mg} / \mathrm{dL}$, frequency of obesity $5-8 \%$ 
and dietary fat intake contains $20-30 \%$ of total calorie intake [4]. Several subgroups of South Asia do have high smoking rates, especially in urban areas. Among the known risk factors, levels of HDL-c have been found to be inherently low in the normal South Asians population. Low HDL-c alone or in combination with high levels of LDL-c, insulin resistance and hypertension constitute a very important intermediate phenotype for CAD. In a recent study on young myocardial infarction patients, $70.3 \%$ were found to have HDL-c lower than $40 \mathrm{mg} / \mathrm{dL}$ [5].

Despite the fact that it is the developing world that will most likely face the epidemic of hypertension (HT) and other chronic diseases [6], Research on cardiovascular diseases in a developing country such as Pakistan has been limited.

This study used a population based survey to measure the prevalence of different CAD risk factors in a Southern Punjab population sample where little is known about CAD, the disease load, and risk factors.

\section{EXPERIMENTAL}

This study was conducted at the Bahawal Victoria Hospital, Bahawalpur, Sheikh Zaid Hospital, Rahim Yar Khan, Chaudhary Pervez Elahi, Institute of Cardiology and Nishtar Hospital, Multan. In addition, these hospitals are large government hospitals of major cities of Southern Punjab- Pakistan. The study (Reference No. 366) was approved from the Ethical Institution Committee, Department of Pharmacy and the Islamia University of Bahawalpur, Bahawalpur- Pakistan.

\section{Population study}

This study was conducted from December 2011 to April 2012 and comprised 200 patients. The patients included in the survey were suffering from acute myocardial infarction and/or they were diagnosed with CAD. They were divided into 6 age groups: 25 - 34, 35 - 44, 45 - 54, 55 64, $65-74$ and $75-84$ years old. All eligible participants gave informed agreement.

\section{Data collection}

The authors prepared questionnaires used to collect such data as demographic information, family health history, dietary habits, physical activity and tobacco use. History of hypertension or its treatment, histories of diabetes mellitus
(DM) or its treatment were recorded after observing their medical reports.

Demographic information comprised sex and age of subjects. Family health history included the presence of $C A D$ in immediate family of patients (mother, father, brother, sister). Dietary history included a subjective account of daily fat and fruit intake. Timing and frequency of meal intake was also recorded. Physical activity was assessed by the occupation and daily physical workout which includes walk for $30 \mathrm{~min}$ or the medium of frequent travelling (bicycle, bike or car). Tobacco use was assessed by asking the patient if he was an active smoker, passive smoker, non-smoker or quitter. If the patient was an active smoker or quitter then he was asked then for how long he had been smoking and how many cigarettes he/she smoked per day.

History of DM and hypertension were positive if a participant has ever been told by a physician to have DM or hypertension or treated accordingly and the medical reports were also checked for further evidence of DM and hypertension if they were available.

Anthropometric features were also recorded which included weight, height, and body mass index (BMI). The weight of participants was determined in subject without foot wear and light clothing using a portable Weighing scale and the height accurately measured with inches tape. Then the BMI was calculated using formula:

Traditional risk factors were defined as follows:

Obesity: $\mathrm{BMI}>30$

Overweight: BMI, between $25-29.9$

Hypertension: Currently taking antihypertensive medications and/ or systolic blood pressure $(\mathrm{SBP})>140$ and/or diastolic blood pressure $(\mathrm{DBP})>90$, by taking the mean of 4 measurements.

Diabetes mellitus: history of using hypoglycemic agents and/or fasting blood sugar $($ FBS $)>126$ and glucose tolerance test (GTT) > 200.

Smoking: consumption of 10 cigarettes per day at least for 3 months.

A person is considered to have an inactive behavior if he walks less than 4-5 km a week, climbs fewer than 20 flights of stairs a week or performs no moderate physical activity (300 $\mathrm{Kcal} /$ day) on 5 days a week.

$C A D$ was diagnosed if the patient had coronary angio-graphic evidence of significant CAD with a greater than $50 \%$ obstruction of at least one 
major coronary artery, a documented myocardial infarction or typical angina pectoris.

\section{Statistical analysis}

Chi square test was applied to analyze the data by Statistical Package for Social Sciences 17.0 software (SPSS). The level of significance was 5 $\%$.

\section{RESULTS}

Prevalence of modifiable and non-modifiable risk factors for CAD, i.e. fatty food consumption, less fruit intake, smoking, obesity, exercise, hypertension, diabetes and family history of CAD was assessed among patients diagnosed with coronary artery disease at a hospital. There is a scarcity of reliable community based epidemiological data on the prevalence of CAD from Southern Punjab and even less is known regarding the prevalence of CAD in the community setting. The 200 participants aged from 25 to 84 years with mean age of 52.7 years in male and 55.8 in female as shown in Table 1.

Family history of CAD was found in $20 \%$ of the total subjects. Presence of family history of CAD in the families of male subjects was $20.83 \%$ and in females was $18.75 \%$. The present study revealed that the most prevalent coronary artery risk factors in Southern Punjab were physical inactivity (52.5\%), hypertension (52\%), poor dietary habits (less fruit intake (48.5\%) and more fatty food consumption (47.5\%), obesity (38\%) and smoking (37\%), respectively. Other less common risk factors were diabetes $(30 \%)$ and family history of CAD (20\%). Almost all of the subjects had more than one CAD risk factors. Based on 10-year age intervals of $25-34,35$ 44, $45-54,55-64,65-74$ and $75-84$, the prevalence of CAD risk factors were standardized based on age and sex distribution of Southern Punjab population. Prevalence of risk factors for CAD in Southern Punjab was given in Table 2.

Physical inactivity was higher in females (65\%) as compared to males (44.17\%). As age increased physical inactivity decreased i.e. 31.8 $\%$ in 25 - 34 year age group while $69.23 \%$ in 65 - 74 year age group and $88.88 \%$ in 75 - 84 year age group. According to the outcomes, the total prevalence of hypertension was $52 \%$ (52.5\% in men and $51.25 \%$ in women). Again the prevalence of hypertension increased with age in both genders. Physical inactivity was prevalent among females by $65 \%$ as compared to $44.17 \%$ in male population.

Less fruit consumption was seen in subjects in lower age groups. As age increased, there was less fruit intake (26.92 \% in 65-74 year and 16.67 $\%$ in 75 - 84 year age groups).

$47.5 \%$ of the total patients had more fatty food intake rich in cholesterol. The trend of fat intake was slightly higher in males $(49.16 \%)$ as compared to females (45\%). Subjects in lower age group i.e. 25 - 34, 35 - 44, 45 - 54 years tended to have higher fat intake. Fatty food consumption decreased as the age increased. It was lowest in 75 - 84 year age group (16.67\%).

Table 1: Distribution of patients in age groups according to location and hospitals

\begin{tabular}{|c|c|c|c|c|c|c|c|c|c|}
\hline \multirow[t]{2}{*}{ Location } & \multirow[t]{2}{*}{ Hospital } & \multirow[t]{2}{*}{ Gender } & \multicolumn{6}{|c|}{ Age range (years) } & \multirow[t]{2}{*}{ Total } \\
\hline & & & $25-34$ & $35-44$ & $45-54$ & $55-64$ & $65-74$ & $75-84$ & \\
\hline \multirow[t]{2}{*}{ Bahawalpur } & \multirow[t]{2}{*}{$\mathrm{BVH}$} & Male & 4 & 8 & 7 & 9 & 5 & 3 & 36 \\
\hline & & Female & 3 & 3 & 2 & 8 & 2 & 1 & 19 \\
\hline \multirow[t]{3}{*}{ Rahim yar khan } & \multirow[t]{2}{*}{$\mathrm{SZH}$} & Male & 3 & 4 & 5 & 7 & 3 & 2 & 24 \\
\hline & & Female & 1 & 4 & 3 & 7 & 2 & 2 & 19 \\
\hline & $\mathrm{NH}$ & Male & 5 & 6 & 8 & 7 & 4 & 3 & 33 \\
\hline \multirow[t]{3}{*}{ Multan } & & Female & 1 & 2 & 2 & 5 & 4 & 3 & 17 \\
\hline & CPEIC & Male & 3 & 5 & 5 & 10 & 2 & 2 & 27 \\
\hline & & Female & 2 & 4 & 4 & 9 & 4 & 2 & 25 \\
\hline Total (N) & & & 22 & 36 & 36 & 62 & 26 & 18 & 200 \\
\hline$\%$ & & & 11 & 18 & 18 & 31 & 13 & 9 & 100 \\
\hline
\end{tabular}

Note: Male: 120; Female: 80, BVH: Bahawal Victoria Hospital, SZH: Sheikh Zayed Hospital, NH: Nishtar Hospital, CPEIC: Chaudhary Pervez Elahi Institute of Cardiology 
Table 2: Prevalence of coronary artery risk factors in Southern Punjab, Pakistan

\begin{tabular}{|c|c|c|c|c|c|c|c|c|}
\hline \multirow{2}{*}{ Age range (years) } & & \multicolumn{7}{|c|}{ Prevalence of Risk Factors (\%) } \\
\hline & & \multirow[t]{2}{*}{$25-34$} & \multirow[t]{2}{*}{$35-44$} & \multirow[t]{2}{*}{$45-54$} & \multirow[t]{2}{*}{$55-64$} & \multirow[t]{2}{*}{$65-74$} & \multirow[t]{2}{*}{$75-84$} & \multirow[t]{2}{*}{ Total } \\
\hline Risk Factors & Gender & & & & & & & \\
\hline \multirow{4}{*}{ Diabetes Mellitus } & Male & 6.67 & 17.39 & 20 & 36.36 & 42.86 & 70 & 29.17 \\
\hline & Female & 14.28 & 15.38 & 27.27 & 34.48 & 41.67 & 50 & 31.25 \\
\hline & Total & 9.09 & 16.67 & 22.22 & 35.48 & 42.31 & 61.11 & 30 \\
\hline & Male & 13.33 & 26.09 & 40 & 78.78 & 71.43 & 90 & 52.5 \\
\hline \multirow[t]{3}{*}{ Hypertension } & Female & 14.28 & 30.77 & 54.54 & 55.17 & 75 & 62.5 & 51.25 \\
\hline & Total & 13.64 & 27.78 & 44.44 & 67.74 & 73.08 & 77.78 & 52 \\
\hline & Male & 13.33 & 17.39 & 44 & 39.39 & 21.43 & 10 & 28.33 \\
\hline \multirow[t]{3}{*}{ Obesity } & Female & 42.86 & 46.15 & 72.72 & 65.51 & 33.33 & 25 & 52.5 \\
\hline & Total & 22.72 & 27.77 & 52.77 & 51.61 & 26.92 & 16.67 & 38 \\
\hline & Male & 60 & 78.26 & 64 & 42.42 & 35.71 & 20 & 53.33 \\
\hline \multirow[t]{3}{*}{ Smoker } & Female & 42.86 & 23.08 & 0 & 6.89 & 8.33 & 12.5 & 12.5 \\
\hline & Total & 54.54 & 58.33 & 44.4 & 25.81 & 23.08 & 16.67 & 37 \\
\hline & Male & 13.33 & 17.39 & 12 & 30.30 & 42.86 & 40 & 24.17 \\
\hline \multirow[t]{3}{*}{ Quitter } & Female & 0 & 0 & 9.09 & 0 & 8.33 & 0 & 2.5 \\
\hline & Total & 9.09 & 11.11 & 11.11 & 16.13 & 26.92 & 22.22 & 15.5 \\
\hline & Male & 66.67 & 60.87 & 60 & 51.51 & 28.57 & 10 & 50.83 \\
\hline \multirow[t]{3}{*}{ Less fruit intake } & Female & 57.14 & 46.15 & 54.54 & 51.72 & 25 & 25 & 45 \\
\hline & Total & 63.33 & 55.55 & 58.33 & 51.61 & 26.92 & 16.67 & 48.5 \\
\hline & Male & 53.33 & 43.48 & 64 & 54.54 & 35.71 & 20 & 49.16 \\
\hline \multirow[t]{3}{*}{ More fatty food intake } & Female & 57.14 & 61.53 & 54.54 & 44.83 & 33.33 & 12.5 & 45 \\
\hline & Total & 54.54 & 50 & 61.11 & 50 & 34.61 & 16.67 & 47.5 \\
\hline & Male & 26.67 & 30.44 & 36 & 45.47 & 64.29 & 90 & 44.17 \\
\hline \multirow[t]{3}{*}{ Physical inactivity } & Female & 42.86 & 46.15 & 63.63 & 68.97 & 75 & 87.5 & 65 \\
\hline & Total & 31.81 & 36.11 & 44.44 & 56.45 & 69.23 & 88.88 & 52.5 \\
\hline & Male & 26.67 & 21.74 & 16 & 21.21 & 21.43 & 20 & 20.83 \\
\hline \multirow[t]{2}{*}{ Presence of disease in the family } & Female & 28.57 & 23.08 & 18.18 & 20.69 & 8.33 & 12.5 & 18.75 \\
\hline & Total & 27.27 & 22.22 & 16.67 & 20.96 & 15.38 & 16.67 & 20 \\
\hline
\end{tabular}

\section{DISCUSSION}

The rise in CVDs reflects a significant change in diet habits, physical activity levels, and tobacco consumption worldwide as a result of industrialization, urbanization, economic development and food market globalization [1]. The American Heart Association has recently focused on physical inactivity as a major modifiable risk factor for heart disease [7]. Prevalence of physical inactivity among females was more because most of the women were housewives with low physical activity. As the age increased physical activity declined. This finding highlights a potential area of emphasis for future educational programs [8].

One study [9] has shown that consumption of fruits and vegetables, particularly green leafy vegetables and vitamin C-rich fruits and vegetables, appear to have a protective effect against coronary heart disease. Many mechanisms are likely responsible for the protective effect of plant-origin foods on cardiovascular diseases. Several epidemiologic studies have reported that vitamins $C, E$, and $\beta$ carotene from the diet or supplements are associated with a lower risk of CHD $[10,11]$.
Saturated fat intake has been related to acute myocardial infarction in adults [12]. Subjects who use ghee for cooking compared with other types of non-hydrogenated oils, a higher percentage of Trans fatty acids, known to increase the risk of ischemic heart disease [1315], has been reported.

In Pakistan, where there is also a problem of under nutrition, in $199411.6 \%$ males and 18.93 $\%$ females were obese or overweight (WHO global database on BMI). The prevalence of obesity, i.e. having BMl greater than 30 was 38 $\%$ in Southern Punjab. Overall, $28.33 \%$ of men and $52.5 \%$ of women had excess weight. The prevalence of obesity, which is strongly associated with CAD, was higher in females. The prevalence of obesity was significantly higher in the subjects of age group $45-54$ year old (52.77 $\%)$ and 55 - 64 year old (51.61\%) as compared to other age groups. Low physical activity and eating habits may be relevant factors that explain the difference between males and females [7].

Almost one-half billion individuals worldwide will eventually die of smoking-related complications [16]. $37 \%$ of subjects were cigarette smokers. The prevalence of smoking was significantly higher in men (53.33\%) as compared to women 
(12.5\%). The highest prevalence of smoking was in the 35 - 44 year old men (78.26\%). Compared with non-smokers, those who consume $\mathbf{2 0}$ or more cigarettes daily have a twofold to threefold increase in total coronary heart disease. Moreover, these effects depend on the number of cigarettes consumed; consumption of as few as one to four cigarettes daily increases coronary artery disease risk, while $15.5 \%$ of the subjects were those who had quit smoking. Number of quitters increased with increasing age, with the highest of $26.92 \%$ in 65 - 74 year age group. Again most of the quitters were men $(24.17 \%)$ as compared to women $(2.5$ $\%)$. Number of smoking quitters increased with increasing age with the highest in men of $65-74$ year age group $(42.86 \%)$.

Pakistan is one of the 10 countries in the world with the highest prevalence of diabetes and has one of the fastest increases in the number of diabetics [17]. The present investigation revealed that about one-third of the 25 - 84 years old population of Southern Punjab is diabetic, 29.17 $\%$ in men and $31.25 \%$ in women. Aging had an increasing influence on the prevalence of diabetes. DM increased from $9.09 \%$ in the $25-34$ year old group to $61.11 \%$ in the 75 - 84 year old subjects. More females were diabetics, although not significantly different as compared to males. This high prevalence in females may be due to low physical activity and/or increase trend in obesity. However, environmental factors such as dietary patterns are more likely to be shared among family members, and this effect will probably be stronger in consanguineous relationships [18].

\section{Limitation of the study}

The study was cross-sectional and therefore, the directionality of the associations could not be determined.

\section{CONCLUSION}

Various risk factors for CAD are highly prevalent in the study population. Though the history of CAD was available in only $20 \%$ of the subjects, the prevalence of individual risk factors ranges from 52.5 to $30 \%$ and approximately all of the subjects have more than one risk factor. Most of these risk factors are modifiable and can be improved by encouraging the patients to adopt a healthy life style such as reducing daily fat intake, increasing fruit and vegetable intake, quitting smoking and engaging in more physical activities. Besides this, screening the community for the presence of diabetes and hypertension combined with proper intervention can reduce morbidity and mortality from this disease.

\section{ACKNOWLEDGEMENT}

The authors acknowledge the moral support given by the Chairman and Dean of the Faculty of Pharmacy \& Alternative Medicine, The Islamia University of Bahawalpur, Pakistan.

\section{REFERENCES}

1. Abbas $S$, Kitchlew AR. Disease burden of ischemic heart disease in Pakistan and its risk factors. Ann Pak Inst Med Sci 2009; 5: 145-150.

2. Godtfredsen NS. Smoking reduction, smoking cessation, and mortality: a 16-year follow-up of 19,732 men and women from the Copenhagen Centre for prospective population studies. Am J Epidemiol 2002; 156: 9941001.

3. Kalra $S$, Narain $S$, Karki $P$, Ansari JA, Ranabhat NK. Prevalence of risk factors for coronary artery disease in the community in Eastern Nepal - A pilot study. J Assoc Physicians India 2011; 59: 300-301.

4. Sing RB, Tomlinson B, Neil TG, Sharma R. Coronary artery risk factors: The South Asia paradox. J Nutr Environ Med 2001; 11: 43-51.

5. Usman A, Frossard PM. Coronary heart disease in south Asia: need to redefine risk. Int J Cardiol 2006; 107: 289290.

6. Kearney PM, Whelton $M$, Reynolds $K$, Muntner $P$, Whelton PK, He J. Global burden of hypertension: analysis of the worldwide data. Lancet 2005; 365: 217223.

7. Fletcher GF, Blair SN, Blumenthal J, Caspersen C, Chaitman B, Epstein $S$, Falls $H$, Froelicher $E S$, Froelicher VF, Pina IL. Statement on exercise: benefits and recommendations for physical activity programs for all Americans. American Heart association. Circulation 1992; 86: 340-344.

8. Dhawan J, Bray CL. Asian Indians, coronary artery disease, and physical exercise. Heart 1997; 78: 550554.

9. Miller ER, Appel LJ, Risby TH. Effect of dietary patterns on measures of lipid peroxidation results from a randomized clinical trial. Circulation 1998; 98: 23902395.

10. Liu S, anson JE. Dietary carbohydrates, physical inactivity, obesity, and the 'metabolic syndrome' as predictors of coronary heart disease. Curr Opin Lipidol 2001; 12: 395-404.

11. Rafiei M, Sadr S, Ansari Z, Namayandeh S, Sadr M. A cross-sectional study of the prevalence of traditional coronary artery disease risk factors in yazd urban population: yazd healthy heart project. Int Cardiovasc Res J 2011; 5: 7-13.

12. Caggiula AW, Mustad VA. Effects of dietary fat and fatty acids on coronary artery disease risk and total and

Trop J Pharm Res, January 2016; 15(1): 199 
lipoprotein cholesterol concentrations: epidemiologic studies. Am J Clin Nutr 1997; 65: 159S-610S.

13. Jacobson M. Cholesterol oxides in Indian ghee: possible cause of unexplained high risk of atherosclerosis in Indian immigrant populations. Lancet 1987; 330: 656658.

14. Willett WC. Ascherio A. Trans fatty acids: are the effects only marginal? Am J Public Health 1987; 84: 722-724.

15. Jafar TH, Levey AS, Jafary FH. Ethnic subgroup differences in hypertension in Pakistan. $J$ Hypertension 2003; 21, 905-912.
16. Jacobs DR. Cigarette smoking and mortality risk: twentyfive year follow-up of the Seven Countries Study. Arch Intern Med 1999: 159, 733-740.

17. Khan A, Ahmad I, Wazir ZM. Prevalence of diabetes mellitus in the North West Frontier Province of Pakistan. J Med Sci 1993; 3: 4-12.

18. Lewington S, Collaboration PS. Age-specific relevance of usual blood pressure to vascular mortality: a metaanalysis of individual data for one million adults in 61 prospective studies. Lancet 2002; 360: 1903-1913. 